\title{
Successful Of Embolization Therapy On Recurrent Massive Hemoptysis because of TB Sequelae
}

\author{
Ratih Dwi Ary Merdekawati ${ }^{1}$,Suryanti Dwi Pratiwi ${ }^{2}$,Ahmad Bayhaqi ${ }^{3}$ \\ ${ }^{12}$ Pulmonology and Respiratory Medicine Department, Medical Faculty of Brawijaya University/Dr.Saiful Anwar \\ Hospital,Malang.Indonesia \\ ${ }^{3}$ Radiology Department, Medical Faculty of Brawijaya University/Dr.Saiful Anwar Hospital,Malang.Indonesia.
}

\begin{abstract}
Background: Haemoptysis is one of vascular lesions in TB sequelae, with incidence of $28 \%$ from 919 cases. It may be recurrent, massive and might cause mortality if left untreated. Embolization procedure with glue and coil can be an alternative to treat patient with recurrent hemoptysis.

Case Report: We reported a case report in Saiful Anwar Malang Hospital, Indonesia, a 34 years old male with intermittent massive haemoptysis. Chest X-ray examination showed Lung Tb far advanced lesion with no acid bacilli found on microbiological examination. Transthoracic FNAB revealed chronic suppurative inflammation, with Cytology sputum Class II. Chest CT Angiography showed Lung TB Far advanced lesions accompanied by mediastinal lymphadenopathy with unsuspecting complications of left supreme intercostal artery aneurysm dd pseudoaneurysm, suggestion embolization. Examination results confirmed the diagnosis of recurrent massive haemoptysis and intercostal artery aneurysm with the history of TB. Embolization procedure was then performed. Conclusion: Angiography CT Scan has better detail in evaluating condition, source, amount, and tract of artery in chest cavity. Bronchial artery embolization as an alternative therapy was found to give better effect of occlusion. Keywords: Massive haemoptysis, chest CT angiography, embolization
\end{abstract}

MRJ 2020; 2(2): 95-100

\section{Introduction}

Tuberculosis (TB) sequelae is a condition that is caused by pathological change in the lung anatomical healing process that needs various management to solve the clinical problem related. Various complications can occur in treated or untreated lung tuberculosis. It can be categorized as parenchymal lesion, airway, vascular, pleura, and systemic complication. Haemoptysis is an example of vascular lesion in TB sequelae, with incidence of $28 \%$ from 19 cases. $^{1}$
Haemoptysis means by bloody expectoration caused by rupture of vasculature inside the lung or from tracheobronchial tree. It is classified as follows: Mild haemoptysis if the volume was less than $25 \mathrm{ml} / 24$ hours, Moderate haemoptysis if the volume was between 25 and $250 \mathrm{ml} / 24$ hours, and Massive haemoptysis if the volume exceeds $600 \mathrm{~mL}$ in 24 hours. Massive haemoptysis mainly originates from rupture of rasmussen anastomosis and may cause mortality if left untreated. ${ }^{2}$

*Corresponding author:

Ratih Dwi Ary Merdekawati (merdekaatauwati@gmail.com)

Pulmonology and Respiratory Department, Saiful Anwar Hospital - Universitas Brawijaya, Jaksa Agung Suprapto St. No. 2, Malang. 65112, Indonesia 
Diagnosis of haemoptysis begins with history and characteristics of bloody cough, relevant physical examination, laboratory examination, and radiology examination to find the source of bleeding, consisting of chest X-ray, chest CT scan and bronchoscopy. Chest multidetector CT (MDCT) must be done in all patients with haemoptysis, including ones with bloodstreaked sputum and bronchiectasis suspect. Chest CT usually reveals hypertrophic orthoptic of left and right bronchial artery, bleeding of pulmonary artery and hypertrophy of non bronchial artery. ${ }^{3,4}$ Maintaining airway patency, adequate oxygenation and stable haemodynamic is crucial in treating patient with haemoptysis. Therapeutic bronchoscopy is indicated in life threatening haemoptysis and haemodynamic disturbances. Other than ensuring adequate ventilation and airway patency, direct haemostasis using rigid bronchoscopy or vasoconstrictor/haemostatic agent can be done. Embolization procedure with glue and coil can be an alternative to treat patient with recurrent hemoptysis. ${ }^{5,6}$

\section{Background}

This case report was published because of the TB sequelae, mainly massive haemoptysis, might cause mortality if left untreated. Direct haemostasis using haemostatic agent can be an alternative therapy in life threatening haemoptysis and haemodynamic disturbances.

\section{Case}

A 34 years old, Javanese male, was presented with intermittent massive haemoptysis that happened for 5 years. Haemoptysis aggravated 4 days before admission, with volume of \pm 500 cc each time the patient coughed. The complaint was followed by dyspnea, malaise and decreased body weight.

Patient had a history of TB 8 years ago and was treated with anti tuberculous drugs for 6 months. After therapy is completed, he is declared cured. The patient worked as a bus conductor.

Anaemic conjunctiva and tachypnea was found in physical examination, while others are within normal limits. Laboratory examination revealed microcytic hypochromic anemia, with haemoglobin $6.20 \mathrm{gr} / \mathrm{dl}$, haematocrit $19.70 \%$, MCV 75 fL and MCH 23.80 pg. Chest X-ray examination showed Lung $\mathrm{Tb}$ far advanced lesion (Fig.1). Microbiology examinations results were as follows: Sputum AFB S/M: No acid fast bacilli is found; Sputum X-pert 
Mtb/Rif: Mtb Not Detected; Sputum culture in

Lowenstein Jensen Media: No growth of acid

fast bacilli; Sputum $\mathrm{KOH}$ : Budding cell and

hyfa negative. Transthoracic Fine Needle

Aspiration Biopsy (FNAB) revealed chronic

suppurative inflammation, with Cytology

sputum Class II. Fiberoptic Bronchoscopy

(FOB) examination was within the normal limit
(Fig.2). Chest CT Angiography showed Lung

TB Far advanced lesions accompanied by

mediastinal lymphadenopathy with

unsuspecting complications of left supreme

intercostal artery aneurysm $\mathrm{dd}$

pseudoaneurysm, suggestion embolization

(Fig.3).
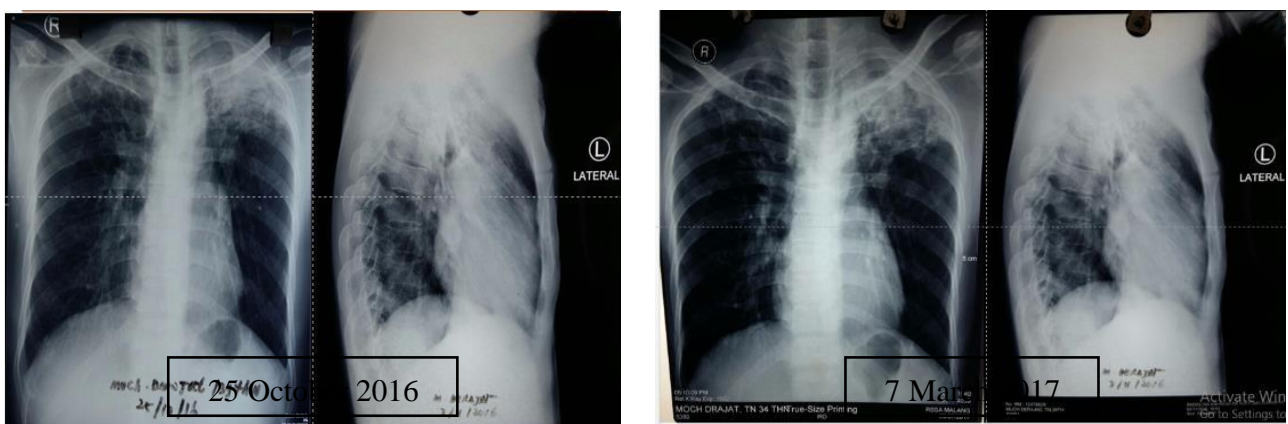

Fig 1. Lung TB far advanced lesion. There is no difference in one year.
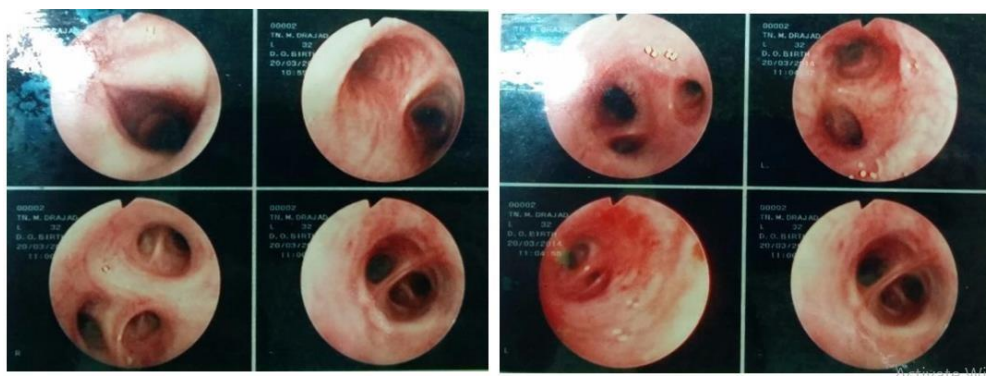

Fig 2. FOB 20 March 2014 at Bangil Hospital. Main Bronchus dextra and sinistra normal limit
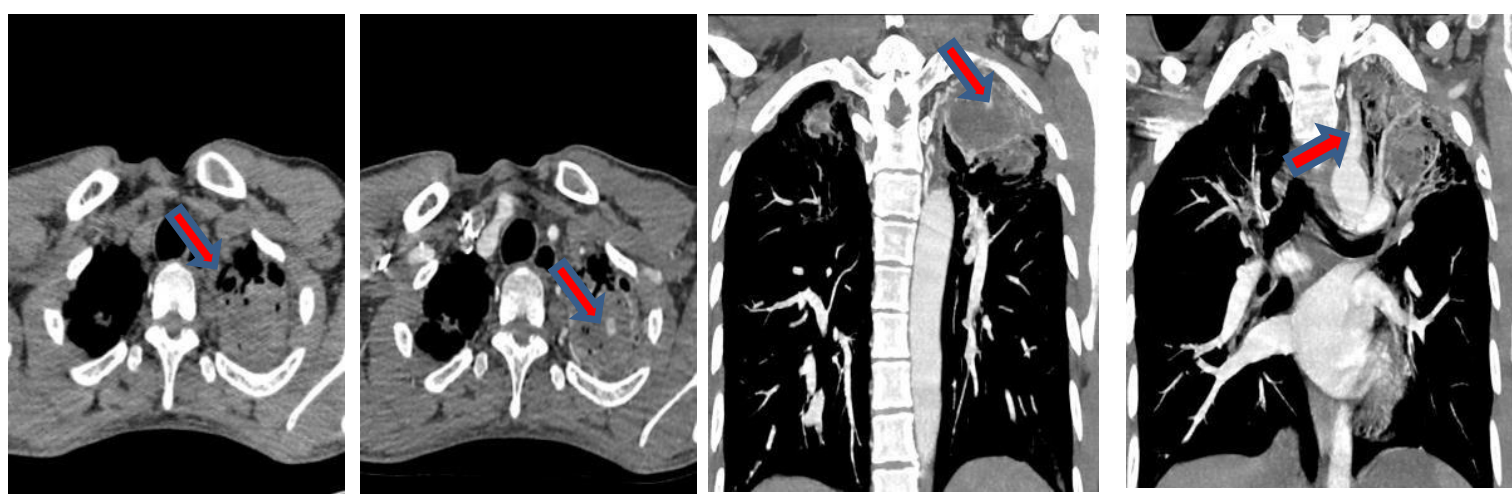

Fig 3. Chest CT showed multiple thick wall cavities with bronchiectasis (left). Contrasting pooling image with a strikingly impressive boundary forms a vein wall located within a cavity from Left Suprema Intercostal Artery. 


\section{Result}

Patient was initially diagnosed with recurrent massive haemoptysis, intercostal artery aneurysm and history of TB.

Ceftriaxone $1 \mathrm{gr}$ was given on the first day twice a day and was stopped at the fourth day of admission (10 March 2017) according to drug sensitivity test result.
Tranexamic acid, codeine, paracetamol and omeprazole was given for symptomatic treatment. Packed Red Cell transfusion was given twice a day for 5 days. Embolization was performed on 27 March 2017 with results as follows (Fig.4,5,6,7,8). After embolization procedure, the patient is still evaluated and monitored clinically.
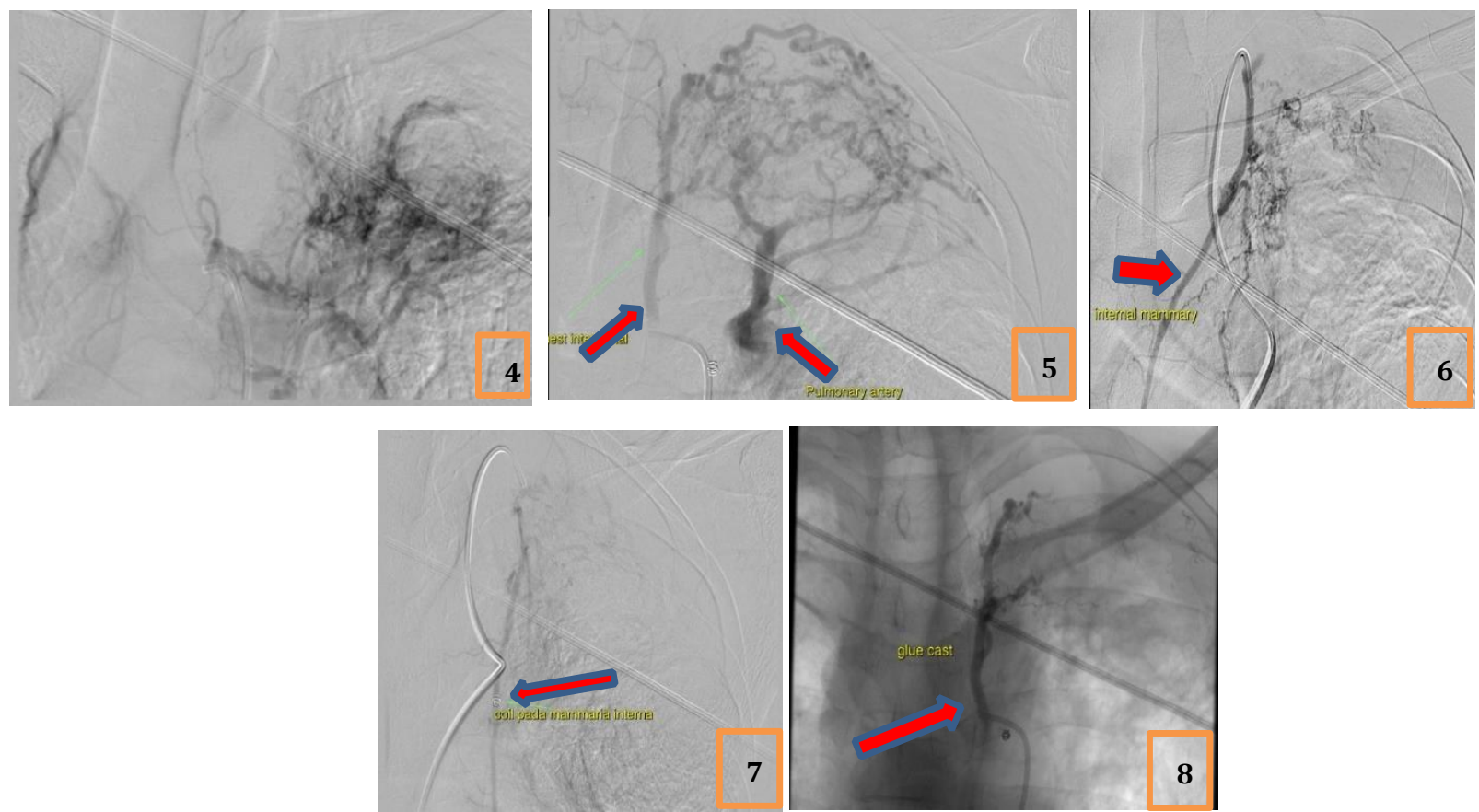

Fig.(4) Left Bronchial Artery, fig.(5) Left Bleeder Apical, left apex with sign of dysplastic vessel that is branched from Suprema Intercostalis Artery (dominant), fig.(6) Left Interna Mammaria Artery, fig.(7) Coiling on the left Interna Mammaria, fig.(8) Lipidol injection mixed glue dyranto 1:2 at left Intercostalis Suprema Artery.

\section{Discussion}

inactive TB. ${ }^{7}$ Many sequeles and complications

Inactive $\mathrm{TB}$ might cause bleeding due to residual bronchiectasis, broncholith erosion through blood vessels and airway, or cavity that may develop into mycetoma. Rupture of can be happened in $\mathrm{TB}$, even it was treated or not. ${ }^{8}$ Haemoptysis in this case was caused by alteration of pulmonary vascular structure (fig. $3,5,6)$.

aneurysm is also an aetiology of haemoptysis in 
CT angiography has role in evaluating mediastinum \& lung parenchym, thoracic vascular structure and most beneficial for planning of embolization or operation. It has accuracy in identifying the source of bleeding in $70-88 \%$ cases. $^{6}$ Figure 9 showed the management of haemoptysis.

In this case, bronchial artery embolization is performed as an alternative therapy in hemoptysis. This procedure is indicated if there was history of failed previous therapy, massive and reccurent hemoptysis, high risk for operation, and to control bleeding temporary before surgery procedure. ${ }^{10}$ Bronchial artery embolization has successful rate of $73-99 \%$ in controlling acute and chronic haemoptysis, with recurrent rate of $10-55 \%$ in 46 months follow up. ${ }^{2,3}$

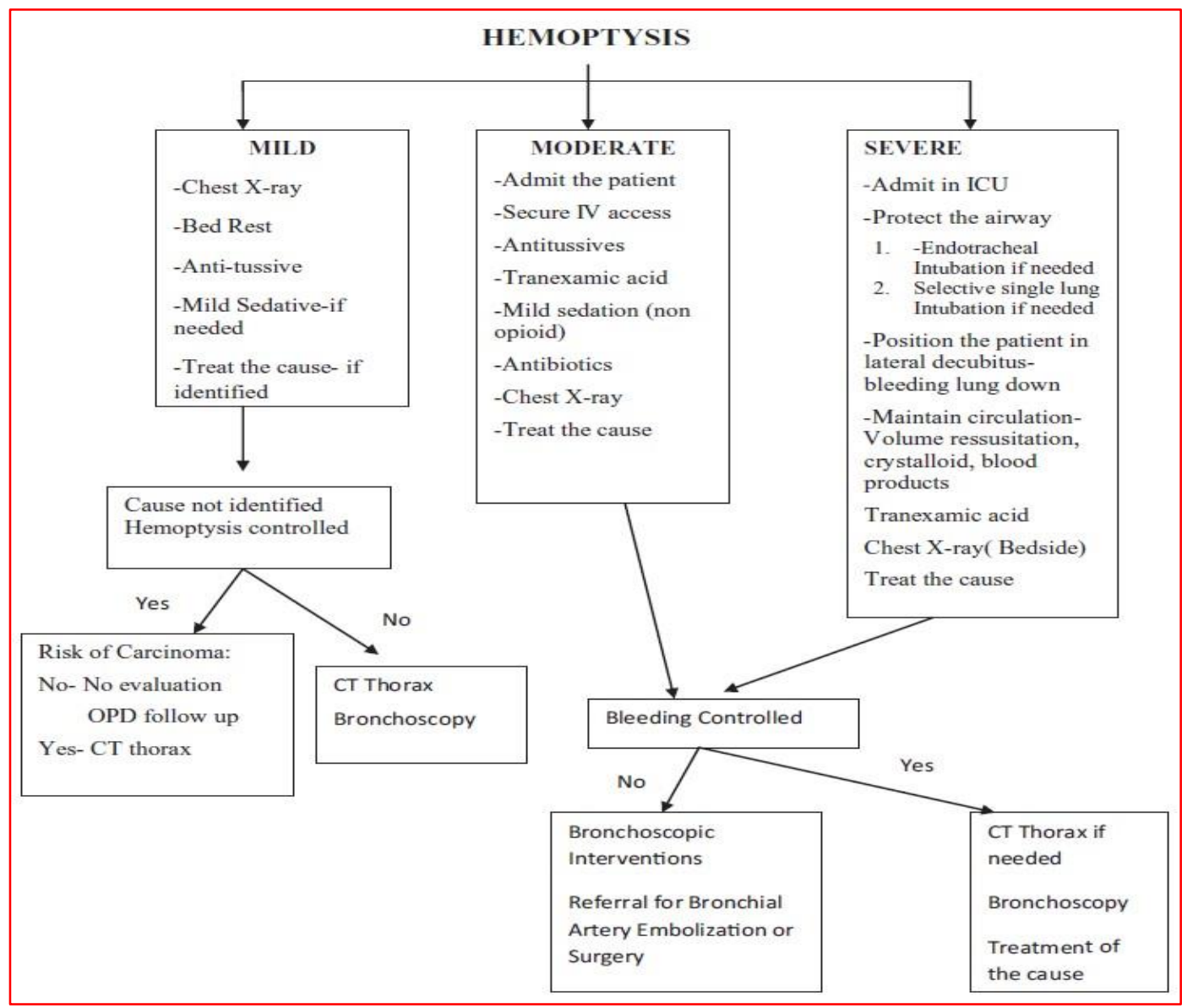

Fig 9. Management of haemoptysis ${ }^{9}$

\section{Conclusion}

This case report presented a 34 years old man, with massive recurrent hemoptysis.
Angiography CT Scan was performed to find condition, source, amount, and tract of artery in chest cavity. Bronchial artery embolization 
performed as an alternative therapy in hemoptysis management with glue embolan and coil in Interna Mammaria Artery and Supreme Intercostalis Artery, and was found to give better effect of occlusion.

\section{Acknowledgements: -}

\section{References}

1. Devi G, 2014.Complication of Pulmonary Tuberculosis.M.S Ramaiah Medical College India. http://www.iconceptpress.com/books/0 40-11/ tuberculosis - a comprehensiveclinicalreference/.

2. Marleen, F.S., Swidarmoko, B., Rogayah, R., Pandelaki, J.,2009 Pulmonologi, D. and Paru, I.K.R.F.S., Embolisasi Arteri Bronkial pada Hemoptisis.J Respir Indones;29(2)

3. Larici, A.R., Franchi, P., Occhipinti, M., Contegiacomo, A., del Ciello, A., Calandriello, L., Storto, M.L., Marano, R. and Bonomo, L., 2014. Diagnosis and management of hemoptysis. Diagnostic and Interventional Radiology, 20(4), p.299.

4. Ananya Panda,Ashu S.,Ankur Goyal.2017.Bronchial artery embolization in hemoptysis : a systematic review.Diagnostic and Interventional Radiology,23,pp.307317.
5. Woo, S., Yoon, C.J., Chung, J.W., Kang, S.G., Jae, H.J., Kim, H.C., Seong, N.J., Kim, Y.J. and Woo, Y.N., 2013. Bronchial artery embolization to control hemoptysis: comparison of Nbutyl2-cyanoacrylate and polyvinyl alcohol particles. Radiology, 269(2), pp.594-602.

6. Cordovilla, R., De Miguel, E.B., Ares, A.N., Povedano, F.J.C., Ortega, I.H. and Merchán, R.J., 2016. Diagnóstico y tratamiento de la hemoptisis. Archivos de bronconeumologia, 52(7), pp.368377.

7. Ingbar DH. (2005). Causes and management of massive hemoptysis in adults.

http://critical.med.ualberta.ca/FileArch ive/ /media/criticalcare/Documents/Ca usesandmanage mentofmassivehemoptysis.pdf

8. Alfred P. Fishman, MD, 2008, Fishman's Pulmonary Diseases and Disorders Fourth Edition, Volumes 1 \& 2, McGraw-Hill Companie.pp. 410415.

9. Singh, S.K. and Tiwari, K.K., 2016. Etiology of hemoptysis: A retrospective study from a tertiary care hospital from northern Madhya Pradesh, India. Indian Journal of Tuberculosis, 63(1), pp.44-47.

10. Sopko DR, Smith TP. (2011). Bronchial artery embolization for hemoptysis. Seminar in Interventional Radiology, 28: 42-62. 